\title{
An Investigation of Multicultural Personality Traits of Iranian High School EFL Learners
}

\author{
Zahra Cheraghi $\mathbb{D i D}^{1}$ and Parisa Karamimehr $\mathbb{1}^{2}$ \\ ${ }^{1}$ English Language Department, Shahid Rajaee Teacher Training University, Tehran, Iran \\ ${ }^{2} M A$ in TEFL, Shahid Rajaee Teacher Training University, Tehran, Iran \\ Correspondence should be addressed to Zahra Cheraghi; z.cheraghi@sru.ac.ir
}

Received 17 November 2021; Revised 18 January 2022; Accepted 20 January 2022; Published 28 February 2022

Academic Editor: Ehsan Namaziandost

Copyright ( 2022 Zahra Cheraghi and Parisa Karamimehr. This is an open access article distributed under the Creative Commons Attribution License, which permits unrestricted use, distribution, and reproduction in any medium, provided the original work is properly cited.

\begin{abstract}
The current study aimed to investigate the Iranian high school EFL learners' multicultural personality traits (MPTs) based on their differences in age. To this end, a convenient sample of 138 junior and senior high school learners aged between 14 and 18 years old were selected. Data were collected through a Multicultural Personality Questionnaire. It measures MPTs (open-mindedness, cultural empathy, emotional stability, social initiative, and flexibility) on a five-point Likert scale. An independent samples $t$-test was used to check the differences between MPTs of junior (14-16) and senior (16-18) high school students. MANOVA was utilized to see the differences between components of MPTs of participants in these two groups. Findings indicated that there is a significant difference between MPTs of junior and senior high school learners in terms of open-mindedness and cultural empathy. That is to say the younger group exhibited more open-mindedness and cultural empathy. Moreover, the results revealed that they were not different in terms of other components of MPTs as social initiative, emotional stability, and flexibility. Besides considering differences between target and native language cultural values and society norms, teachers should attempt to improve students' cultural empathy and open-mindedness in order to gain the students' knowledge of language and attain educational purposes.
\end{abstract}

\section{Introduction}

English is identified by its native and second language speakers as well as its geographical distribution and its application in organizational and diplomatic contexts [1]. Therefore, learning English becomes the essential issue for the whole world. The question here is learning English is not just learning the language. According to Stein [2], it is impossible to teach or learn a language without its culture, for culture is the necessary content for language use. According to Vygotsky's theory of language and thought, language, thought, and culture are interrelated. Culture has taken an important place in foreign language teaching and learning studies. It has been widely recognized that culture and language is used as a main medium through which culture is expressed [3]. It can be stated that a language is a part of culture and a culture is a part of a language. The two are intricately interwoven so that one cannot separate the two without losing the significance of either language or culture [4]. Since every culture has its own cultural norms for conversation and these norms differ from one culture to another, some of the norms can be completely different and conflict with other cultures' norms. Consequently, communication problems may arise among speakers who do not know or share the norms of other culture. To solve the communication problems in the target language in the EFL classrooms, the learners need to learn the target culture within the syllabus, and the teachers should be sensitive to the learner's fragility so as not to cause them to lose the motivation [3]. It is also known that the students, who are in need of developing cultural awareness and cultural sensitiveness, are normally those who are least disposed toward these goals. Teacher's task is to make students aware of cultural differences and not pass value judgments on these 
differences. Students learning a foreign language have to assimilate many new categorizations and codifications if they are to understand and speak the language as its native speakers do.

Language and culture are so inextricably intertwined that one's existence without the other is almost inconceivable, and every speaker's personal identity is primarily established on the foundation of these two elements employed in social interactions [5]. Li [6] asserted that language, culture, speech community, and identity are intertwined. Therefore, it can be concluded that a seamless bond between culture and language creates a unified body, and it becomes very difficult to have cases of L2 learning without its culture (C2) instilling itself upon the learning process that will have its due influence on language learners' personality traits and attitudinal behavior. Language, culture, and identity are three dimensions of a triangle within which individuals exercise their social beings. Identity construction, even in the context of the first language, is a lifelong process and in the context of L2 learning, which brings about the possibility of exposure to a second culture, can be of a greater sensitivity [5]. EFL students have spent considerable time of their daily lives negotiating meanings and intentions in English; therefore, there exists potential for acquiring altered personality features.

According to Kramsch [7], culture refers to the affiliation in a discourse community in which a common system of already set standards is shared among members to perceive, believe, evaluate, and act upon life. Through learning of the culture individuals acquire an understanding of what they need to do in order to operate in a manner conventional to other community members. Matsumoto and Juang [8] defined human culture as a system of information with a meaning uniquely comprehended by a group and handed down to other generations, which provides the group with the means to satisfy basic needs to survive, promote happiness and well-being, and grasp the underlying meaning of life. Baumeister, Ciarocco, DeWall, and Twenge [9] viewed culture as an information-based system that equips people with the tools to fulfill their needs and also coexist and live in groups. Schwartz et al. [10] asserted that culture is a latent construct and can only be deciphered through intricate variables that give specific meaning to life in a certain social system. From this standpoint, it can be said that the average of individuals' values, beliefs, and behaviors do not independently explain culture, but rather these values, beliefs, and behaviors are observed and signified due to the individuals' responses to the culture [11]. Cognitive psychologists often use "culture" to convey the meaning of a range of knowledge which solely humans have gained throughout the history to address the nature of cognition in human as opposed to nonhuman species [12]. Culture is the social behavior and norms found in human societies.

It is acknowledged that language is a part of culture. Linguists and anthropologists have recognized that the forms and employments of a language relies upon the cultural part of the community which implies that linguistic competence is insufficient for learner to be suitable in that language [1]. Language and culture are reciprocally related, and therefore, by learning a language, a huge part of its own culture is either consciously or unconsciously transferred to an individual [13].

Fishman [14] explained that language and culture are jointed at three links:

(1) A language indexes its culture. Historically, language and its respective culture will have harmoniously developed together over a long period of time. Therefore, the language that has wound around a culture demonstrates the core of that culture. Its vocabulary, idioms, and metaphors are the components that best offer understanding of that culture at a cognitive and emotive level.

(2) A language is the symbol of its culture. A language displays the status of the culture to which it is connected. For instance, speaking English in Kuwait after winning the war against Saddam Hussein of Iraq was considered as an indication of status, power, and victory [15]. To many, English typically symbolizes modernity, affluence, wealth, and accomplishment. Some people think that a dying language symbolizes menial status and meager income.

(3) Culture partly stems from its language. A great deal of a culture is verbally passed down and acted upon. Cultural elements like the poetry, its folk tales and shrewd sayings, greeting and leaving conventions, history, wisdom, and ideals are all packaged in its language [15]. It is the language that adds color and taste to culture and preserves its memories.

People experience another language with its culture. It means that, when individuals speak other languages, they experience two different identities. Some may lose traditional, religious, political, and national identity and adapt himself to the target culture; whereas, others may be irreconcilable in a way that cannot cope with the target culture. Here, it seems that the one would reach his purpose if he could restore his identity to the balance of globalization. According to Alfarhan [16], globalization of English has led to various changes in a number of ways and one outcome could be loss of cultural identity. Languages carries identity. Identity entails the common characteristics of group members, community, or region. Identity ensures the security and status of the existence shared by individuals. Identity is sometimes and somehow implied through dress, religious beliefs, and rituals, but language is almost always present in the formation of identity and demonstration of identity. Language indexes, marks, and basically symbolizes identity [15].

As regards learners' personality, it is about how a learner thinks, feels, believes, and behaves. Personality is described as the set of specific behaviors, cognitions, and emotional patterns that develop from biological and environmental factors [17]. Ponterotto et al. [18] referred to the multicultural personality as an array of traits, attitudes, and behaviors that prepare individuals to make successful evolutionary adaptations in response to different cultural settings. Conceptually, the roots of the multicultural 
personality can be traced in its application in clinical and counseling psychology in the United States and personnel psychology in the Netherlands. Ramirez [19] with work experience in the southwest region of the United States asserted the multicultural personality to be a synthetic set of resources acquired from various cultures that enable people to enhance cultural versatility in navigating through different cultural environments.

According to Ponterotto et al. [18], multicultural personality is recognized by an emotionally stable individual who is secure in their racial, ethnic, and other identities and eagerly accepts diversity in their personal life and try to learn about other cultures and interact with people coming from different cultures. There is spiritual essence to every individual that has some sense of attachment to others, enables empathy in various contexts, is self-reflective and cognitively flexible, shows a sense of humor, effectively steer, and deals with multiple roles and cultural contexts [18]. Furthermore, he or she has the ability to live and work usefully and productively among different groups and people of different types, realizes the biases hardwired in his/her own worldview and tends to actively find out about alternate worldviews, understands the influence of inherent racism and homophobia or undeserved privilege in their personal life, and is a social activist, brave enough to speak out against all forms of social injustice [18].

Some traits of multicultural personality are cultural empathy, open-mindedness, social initiative, emotional stability, and flexibility [20].

These traits briefly defined as follows.

Ruben [21] defined cultural empathy as an individual's interest in other people and a sensitivity to and mindfulness of others' feelings and beliefs.

Open-mindedness refers to the absence of strong prejudices against other cultures including those people's behaviors and cultural habits and to have a flexible attitude towards those groups [22].

Social initiative is a reflection of the individuals' tendency to actively approach novel social situations and to take the first steps [23].

As Leone et al. [23] believed, emotional stability is described as the ability to maintain calmness in stressful awkward environments and circumstances and to perform appropriately.

Flexibility is referred to as an individual's adaptive ability to shift from familiar, habitual, and long held behaviors to new standards and procedures that promote adaptation to the new cultural circumstances [23].

As Grumpers [24] stated, awareness of the relationship between language and culture has always been particularly important for language learners, language teachers, and generally language instruction. In such a way that they know culture as one of the most influential parameters in language learning, especially teaching English in EFL contexts. EFL students in their EFL learning process are exposed to a new valorization system that makes them appropriate subjects and samples for cross-cultural studies and multicultural personality traits [5]. EFL students due to their associations with the English language are experiencing a bilingual life in the foreign language context. Their coexistence with English language will have potential influence on their perceptions of the external world and the conception of values. These cultural features call for a thorough scientific study and analysis.

Up to now, no study considered the role of EFL learners' age and their multicultural personality trait in the context of Iran. Therefore, this study is an attempt to reveal the role of age and amount of time spent learning English in Iranian EFL teenage learners' multicultural personality traits that leads to the following research questions:

(1) Is there any statistically significant difference between multicultural personality traits of 14-16 and 16.1-18-year-old English language learners?

(2) Is there any statistically significant difference between multicultural personality traits' components (open-mindedness, cultural empathy, social initiative, emotional stability, and flexibility) of 14-16 and 16.1-18-year-old English language learners?

\section{Literature Review}

According to the previous contributions and the role of learning English on individuals' culture, precisely personality, studies have shown that cultural interactions, whether migration to other countries, or learning a foreign language (English) in EFL context mainly lead to a change in the cultural structure of individuals positively and negatively as cultural adaptation, acculturation, culture shock, culture trauma, cultural attachment, and cultural detachment [25]. It is important that language learners and language teachers would be aware of the impacts that language learning may have on learners and the way their attitudes toward the world, particularly culture values and the society norms may change.

Several research studies related to the present study would be reviewed.

A research was conducted by Gojkov-Rajić and Prtljaga [26] to investigate the relation between foreign language learning and intercultural tolerance. The aim of this study is to examine whether-or-not foreign language learning has any impact on the increase of intercultural tolerance. It considers the influence of a new foreign language on changes taking place in the learners' attitudes to other nations. Thus, it could be assumed that foreign language positively influences intercultural tolerance. The results reveal that the acquisition of foreign languages, particularly at an early age, followed by the gaining knowledge of the nations and cultures related to the language broadens people's horizon to the unknown and offers them more tolerance to diversity and therefore prepares them to accept life not only in multi but also in intercultural world.

Another study by Mikhaleva and Régnier [27] with the aim to address the issue of parallel study of native and target language cultures in foreign language teaching consider studying both native and target language cultures of high importance for students' personal development while they acquire a foreign language. In this article, it hypothesized 
that the use of a foreign language would diminish the vividness of mental imagery and that this would have consequences for choice. The endings suggest that our mental images change when using a foreign tongue, leading to downstream consequences for how we make decisions.

Alfarhan [16] investigated the concepts of English globalization and its impact on cultural identity. The study attempted to examine how learners of English as a second language use English at the expense of their mother tongue and how second language acquisition affects or reshapes one's cultural identity. The results imply the globalization of English has substantially contributed to the loss of cultural identity of those who acquire second English language.

A study conducted by Khatib and Bahrami [5] examined the Iranian EFL learners' multicultural developmental trend in light of investment hypothesis as they furthered their academic studies from BA toward postgraduate levels. The results indicated that EFL Iranian students' MPTs improved as they furthered their academic career from BA to MA and from MA to Ph.D. levels. The study concluded that advancement in EFL students' academic career resulted in a concomitant development in their MPTs, and among the five MPTs, cultural empathy and social initiative were found to have been significantly improved at Ph.D. level.

As far as the researchers know, this work is the only research which was done about multicultural personality traits of EFL learners in Iran. In this work, the researchers just studied the students' MPTs based on their academic studies, and they neglect the role of age; therefore, the current study considered the importance of EFL learners' age and their MPTs. The reason for this importance is the sensitivity of participants' age and the instability of their identity. It is worth mentioning that knowing the change in factors of EFL learners MPTs based on their age could be a great help for language teachers and EFL learners to obtain educational purposes.

Taking prior research studies related to the present study, it seems that no study has focused on Iranian teenage learners' multicultural personality traits, and this issue has not received its deserved attention. To fill this void, the current study aims to investigate the multicultural personality traits of (junior and senior high school) 14-16 and 16.1-18 EFL learners.

\section{Methods}

3.1. Participants. A convenient sample of 138 Iranian high school EFL learners aged between 14 and 18 years old participated in this research from different high schools in Tehran. There were two random groups of junior and senior high school students from different social backgrounds. Based on gathered information from 138 questionnaires, it was found that there were 15 Turkish, 7 Kurdish, and 6 Afghan bilinguals. Also, 4 participants were from Mashhad, 4 from Luristan, and 2 from Nishapur, and they were bilingual as well. In order to avoid cultural interference of bilingualism, these participants were excluded from the research. Therefore, the effect of other languages such as Turkish and Kurdish on students' MPTs was controlled and just the effect of English language on monolingual (Persian) students was considered. Moreover, to control the effect of gender, girl students were selected and boys were not included in the current study. The reason of selecting girls than boys was their availability. Then, 100 students were left. Remaining 100 data classified in two groups based on age differences. Group one contained 14-16 (junior high school) and group two contained 16-18-year-old (senior high school) English language learners.

3.2. Instruments. Multicultural Personality Questionnaire (MPQ) was used to measure the multicultural personality traits (MPTs) of the participants. It is developed by Van Der Zee and Oudenhoven [28] at Groningen University in the Netherlands. MPQ, a 50-item questionnaire, measures multicultural personality traits (open-mindedness, cultural empathy, social initiative, emotional stability, and flexibility) on a five-point Likert scale. It is used to find out how easy or troublesome it is for learners to acclimate to other cultures in bicultural and multicultural contexts, how easy they can learn English and adapt to other cultures without any cultural confusion and identity loss.

3.3. Procedures. Multicultural Personality Questionnaire, a 50-item questionnaire, was translated to Persian by the researchers. The choice of Persian rather than English language for the questionnaire was to ensure the clarity of items and also equal level of understanding for all the participants. The content validity of the questionnaire was examined by four language experts (members of the faculty of English) who made some suggestions regarding suitability, addition, or reduction of some items. The aim was to compare every translated item with its original English version to see if there is any gap or ambiguity, and the language is clear. The Persian version of 50-item MPQ was pilot-administered to some available learners both girls and boys (boys were limited in number (10 people), so the researcher excluded those few boys to control the effect of gender). Next step was distributing questionnaires to some high schools. Then, the data were collected from 138 students during one semester.

\section{Findings}

Descriptive and inferential statistics were used to answer the research questions. In order to analyze data, the Statistical Package for Social sciences (SPSS) version 19 was used. Regarding the first research question, to compare MPTs of 14-16 and 16.1-18-year-old high school EFL learners, an independent samples $t$-test was run. And also, a one-way MANOVA analysis was performed in order to answer the second research question of this study (i.e., to compare the MPTs' components of 14-16 and 16.1-18-year-old high school EFL learners).

Table 1 provides the descriptive statistics for two groups of participants' aged 14-16 and 16-18 (junior and senior high school learners). It was observed that from 100 individuals, 47 individuals (47\%) were $14-16$ years old and 53 individuals $(53 \%)$ were $16-18$ years old. 
Table 2 provides the descriptive statistics for the participants' MPTs as a unit and its components (openmindedness, cultural empathy, social initiative, emotional stability, and flexibility) separately. It presents the descriptive statistics of the variables such as mean, standard deviation, variance, mode, and median. The total mean of 100 participants' MPTs was 110.99. Among the components means of MPTs, the highest mean was for individuals' emotional stability (28.14), and the lowest mean was for individuals' open-mindedness (14.48). It can be realized that students with high emotional stability can withstand troublesome circumstances and handle difficulty.

Table 3 provides the reliability statistics of the instrument used in this study. Cronbach alpha was performed for 50 items. It demonstrates that the reliability index is 7 for 50 items which is satisfactory.

In our field of study. Cronbach's alpha could be a degree of inner consistency, that is, how closely related a set of things are as a bunch. It is considered to be a degree of scale reliability.

To answer the first research question, it is useful to transfer it into a null hypothesis. The hypothesis reads as there is not any statistically significant difference between multicultural personality traits of 14-16 and 16-18-year-old high school EFL learners. In order to test this hypothesis, the researcher had to run an independent samples $t$-test. Before presenting the $t$-test results, descriptive information is given in Table 4. As given in Table 4, the mean for 14-16-year-old students is 115.57 and the mean for 16-18-year-old students is 106.92. The younger group obtains a higher mean.

In order to see whether the difference between two groups is statistically significant or not, an independent samples test was run. Based on Table 5, the mean difference is statistically significant, $t(98)=3.37, p=0.001, \mathrm{CI}=95 \%$. The null hypothesis is rejected. Hence, it is safe to say that the younger (14-16-yearold) learners exhibit a higher index of personality, that is, the younger group MPTs were higher than the other group.

Based on Table 6, correlations are well below 0.8; there is no concern of violating the assumption of multicollinearity and singularity.

As it was mentioned previously, personality is composed of of five traits, namely, cultural empathy, open-mindedness, social initiative, emotional stability, and flexibility. To see where exactly the difference between the two age ranges studied here lies, the researcher needs to run a multivariate analysis of variance (MANOVA). This leads to the second research question. To investigate the second research question, it was formulated into the following null hypothesis: there is not any statistically significant difference between multicultural personality traits' components (cultural empathy, open-mindedness, social initiative, emotional stability, and flexibility) of 14-16 and 16.1-18-year-old English language learners. To test this hypothesis, a one-way MANOVA was run, the results of which are given in Table 7.

Check for multicollinearity and singularity correlation among variables was run. The obtained results are given in Table 7. An examination of "between subjects effects" in Table 7 shows that the difference between 14-16 and 16.1-18 age range in terms of cultural empathy $(F(1,99)=7.44$,
TABle 1: Population distribution based on age.

\begin{tabular}{lcc}
\hline Age & $f$ & Percentage \\
\hline $14-16$ years old & 47 & 47 \\
$16-18$ years old & 53 & 53 \\
Total & 100 & 100 \\
\hline
\end{tabular}

TABLE 2: Descriptive statistics of the research variables.

\begin{tabular}{lccccc}
\hline Variables & Mean & SD & Variance & Mode & Median \\
\hline MPTs & 110.99 & 13.43 & 180.39 & 101 & 109.50 \\
Cultural empathy & 20.48 & 3.29 & 10.83 & 21 & 20 \\
Open-mindedness & 14.48 & 3.48 & 12.13 & 14 & 15 \\
Social initiative & 21.92 & 4.38 & 19.22 & 19 & 21.5 \\
Emotional stability & 28.14 & 4.90 & 24.08 & 27 & 8 \\
Flexibility & 23.30 & 4.50 & 20.31 & 21 & 24 \\
\hline
\end{tabular}

TABLE 3: Reliability statistics.

\begin{tabular}{lc}
\hline Cronbach's alpha & No. of items \\
\hline 0.705 & 50 \\
\hline
\end{tabular}

TABle 4: Group statistics for age range.

\begin{tabular}{cccccc}
\hline & Age range & $N$ & Mean & Std. deviation & Std. error mean \\
\hline \multirow{2}{*}{ Total } & $14-16$ & 47 & 115.5745 & 13.08624 & 1.90882 \\
& $16.1-18$ & 53 & 106.9245 & 12.49438 & 1.71624 \\
\hline
\end{tabular}

$p=0.008, \mathrm{y}=0.071)$ and open-mindedness $(\mathrm{F}(1,99)=$ 9.53, $p=0.003, y=0.089$ ) is statistically significant, that is to say the younger group of learners exhibit more cultural empathy and more open-mindedness than the older group.

The table further provides the readers with indices of social initiative (F $(1,99)=2.87, p=0.093, y=0.029)$, emotional stability $(\mathrm{F}(1,99)=2.91, p=0.091, \mathrm{y}=0.029)$, and flexibility $(\mathrm{F}(1,99)=2.58, p=0.111, \mathrm{y}=0.0826)$. These three indices tell us that there is no significant difference between younger and older groups of learners in terms of social initiative, emotional stability, and flexibility.

An examination of "between subjects effects" in Table 7 shows that the difference between 14-16 and 16.1-18 age range in terms of cultural empathy $(F(1,99)=7.44$, $p=0.008, \mathrm{y}=0.071)$ and open-mindedness $(F(1,99)=9.53$, $p=0.003, y=0.089)$ is statistically significant. That is to say, the younger group of learners exhibit more cultural empathy and more open-mindedness than the older group. The table further provides the readers with indices of social initiative $(F(1,99)=2.87, p=0.093, \mathrm{y}=0.029)$, emotional stability $(F$ $(1,99)=2.91, p=0.091, \mathrm{y}=0.029)$, and flexibility $(F(1$, $99)=2.58, p=0.111, \mathrm{y}=0.0826)$. These three indices tell us that there is not a significant difference between younger and older groups of learners in terms of social initiative, emotional stability, and flexibility.

\section{Discussion}

The present study aimed to investigate the Iranian high school EFL learners' multicultural personality traits (MPTs) based on their differences in age. It further attempted to see 
TABLE 5: Independent samples test for age range.

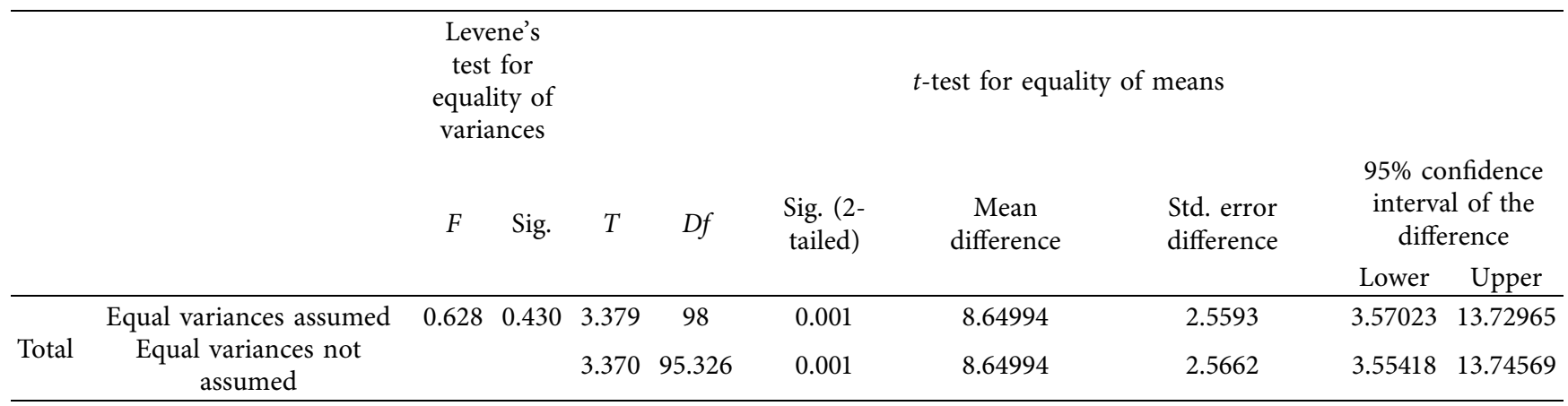

TABLE 6: Correlations among variables of personality.

\begin{tabular}{|c|c|c|c|c|c|c|}
\hline & & Cultural empathy & Open-mindedness & Social initiative & Emotional stability & Flexibility \\
\hline \multirow{3}{*}{ Cultural empathy } & Pearson correlation & 1 & $0.250^{*}$ & -0.052 & $0.247^{*}$ & -0.032 \\
\hline & Sig. (2-tailed) & & 0.012 & 0.608 & 0.013 & 0.750 \\
\hline & $N$ & 100 & 100 & 100 & 100 & 100 \\
\hline \multirow{3}{*}{ Open-mindedness } & Pearson correlation & $0.250^{*}$ & 1 & $0.278^{* *}$ & $0.382^{* *}$ & $0.277^{* *}$ \\
\hline & Sig. (2-tailed) & 0.012 & & 0.005 & 0.000 & 0.005 \\
\hline & $N$ & 100 & 100 & 100 & 100 & 100 \\
\hline \multirow{3}{*}{ Social initiative } & Pearson correlation & -0.052 & $0.278^{* *}$ & 1 & $0.254^{*}$ & $0.338^{* *}$ \\
\hline & Sig. (2-tailed) & 0.608 & 0.005 & & 0.011 & 0.001 \\
\hline & $N$ & 100 & 100 & 100 & 100 & 100 \\
\hline \multirow{3}{*}{ Emotional stability } & Pearson correlation & $0.247^{*}$ & $0.382^{* *}$ & $0.254^{*}$ & 1 & $0.467^{* *}$ \\
\hline & Sig. (2-tailed) & 0.013 & 0.000 & 0.011 & & 0.000 \\
\hline & $N$ & 100 & 100 & 100 & 100 & 100 \\
\hline \multirow{3}{*}{ Flexibility } & Pearson correlation & -0.032 & $0.277^{* *}$ & $0.338^{* *}$ & $0.467^{* *}$ & 1 \\
\hline & Sig. (2-tailed) & 0.750 & 0.005 & 0.001 & 0.000 & \\
\hline & $N$ & 100 & 100 & 100 & 100 & 100 \\
\hline
\end{tabular}

if there is any statistically significant difference between multicultural personality traits' components (open-mindedness, cultural empathy, social initiative, emotional stability, and flexibility) of 14-16 and 16.1-18-year-old English language learners. To this end, differences between MPTs of two groups of 14-16 and 16-18year-old girl students were examined.

Considering the first research question, the result of this research confirmed that there is a statistically significant difference between multicultural personality traits of 14-16 and 16.1-18-year-old high school learners. 14-16-year-old participants present higher mean which means that MPTs (multicultural personality traits) of this group were higher than the other group. Therefore, learning English had a role in changing MPTs of younger participants. Besides, a review article by Mikhaleva and Régnier [27] considered studying both native and target language cultures to be essential for students' personal development in the process of foreign language learning. The endings suggest that our mental images change when using a foreign tongue, leading to downstream consequences for how we make decisions [29]. In this regard, the result of the study corroborated the findings of Mikhaleva and Régnier' study [27]. As the mental images changed when using a foreign language, MPTs of high school learners in the current study changed in the process of learning a foreign language. Mental imagery plays an important role in the way we feel, think, and even behave.
These mental simulations are often guided by language, making it important to understand what aspects of language contribute to imagery vividness and consequently to the way we think [29].

Regarding the second research question, the findings of this study revealed that there is a significant difference between cultural empathy and open-mindedness of both two groups (age range of 14-16 and 16.1-18). The younger group showed more cultural empathy and open-mindedness than the older group which means that learning a foreign language (English) had a role in changing these traits of their MPTs. In spite of these changes, it observed no statistically significant difference between other traits of their MPTs such as social initiative, emotional stability, and flexibility.

The result of this study claimed that the younger the EFL learners, the higher their MPTs, especially open-mindedness and cultural empathy. An open-minded EFL learner can consider ideas and opinions that are new or different to his or her own. In other words, an EFL learner with high openmindedness can easily deal with new language and culture and rarely experience culture shock. Another trait, cultural empathy, is an appreciation and resistance of societies that are distinctive from one's own. Like numerous convictions and states of mind, social compassion starts to create when we were children and is strengthened or challenged over time by observing others and through life encounters. By improving these two traits (cultural empathy and open- 
TABLE 7: Tests of between-subjects effects for age range.

\begin{tabular}{|c|c|c|c|c|c|c|c|}
\hline Source & Dependent variable & Type III sum of squares & $D f$ & Mean square & $F$ & Sig. & Partial eta squared \\
\hline \multirow{5}{*}{ Corrected model } & Cultural empathy & $75.754^{\mathrm{a}}$ & 1 & 75.754 & 7.445 & 0.008 & 0.071 \\
\hline & Open-mindedness & $106.556^{\mathrm{b}}$ & 1 & 106.556 & 9.538 & 0.003 & 0.089 \\
\hline & Social initiative & $54.247^{\mathrm{c}}$ & 1 & 54.247 & 2.875 & 0.093 & 0.029 \\
\hline & Emotional stability & $68.873^{\mathrm{d}}$ & 1 & 68.873 & 2.915 & 0.091 & 0.029 \\
\hline & Flexibility & $51.739^{\mathrm{e}}$ & 1 & 51.739 & 2.588 & 0.111 & 0.026 \\
\hline \multirow{5}{*}{ Intercept } & Cultural empathy & 42005.834 & 1 & 42005.834 & 4128.106 & 0.000 & 0.977 \\
\hline & Open-mindedness & 22127.156 & 1 & 22127.156 & 1980.540 & 0.000 & 0.953 \\
\hline & Social initiative & 48069.247 & 1 & 48069.247 & 2547.593 & 0.000 & 0.963 \\
\hline & Emotional stability & 79180.873 & 1 & 79180.873 & 3351.691 & 0.000 & 0.972 \\
\hline & Flexibility & 54294.499 & 1 & 54294.499 & 2715.748 & 0.000 & 0.965 \\
\hline \multirow{5}{*}{ Age range } & Cultural empathy & 75.754 & 1 & 75.754 & 7.445 & 0.008 & 0.071 \\
\hline & Open-mindedness & 106.556 & 1 & 106.556 & 9.538 & 0.003 & 0.089 \\
\hline & Social initiative & 54.247 & 1 & 54.247 & 2.875 & 0.093 & 0.029 \\
\hline & Emotional stability & 68.873 & 1 & 68.873 & 2.915 & 0.091 & 0.029 \\
\hline & Flexibility & 51.739 & 1 & 51.739 & 2.588 & 0.111 & 0.026 \\
\hline \multirow{5}{*}{ Error } & Cultural empathy & 997.206 & 98 & 10.176 & & & \\
\hline & Open-mindedness & 1094.884 & 98 & 11.172 & & & \\
\hline & Social initiative & 1849.113 & 98 & 18.868 & & & \\
\hline & Emotional stability & 2315.167 & 98 & 23.624 & & & \\
\hline & Flexibility & 1959.261 & 98 & 19.992 & & & \\
\hline \multirow{5}{*}{ Corrected total } & Cultural empathy & 1072.960 & 99 & & & & \\
\hline & Open-mindedness & 1201.440 & 99 & & & & \\
\hline & Social initiative & 1903.360 & 99 & & & & \\
\hline & Emotional stability & 2384.040 & 99 & & & & \\
\hline & Flexibility & 2011.000 & 99 & & & & \\
\hline
\end{tabular}

mindedness) in older EFL learners (16-18 years old), learning the target language and culture will be easier and faster. To this end, teachers can utilize diverse learning materials to create a tolerant environment.

However, the findings of this study were not in agreement with Khatib and Bahrami's [5] study which revealed that advancement in EFL students' academic career resulted in a concomitant development in their MPTs. In the article by Khatib and Samadi Bahrami [5], it was concluded that advancement in EFL students' academic career resulted in a concomitant development in their MPTs, and among the five MPTs, cultural empathy and social initiative were found to have significantly improved at Ph.D. level. This contrast between the findings of the present study and findings of the previous work is that in this study, MPTs of 14-16 years old EFL learners were higher than the MPTs of 16-18 in terms of open-mindedness and cultural empathy. But in the their article, MPTs of Iranian students improved as they furthered their academic career from BA to MA and Ph.D levels. The contrast might arise from the focus of their study which was based on the participants' level of education and not their age.

Moreover, the article by Alfarhan [16] investigated the concepts of English globalization and its effects on cultural identity. Therefore, he found out that language has a great impact on cultural identity, that is, as soon as one loses the language, he/she also loses the cultural identity. He also asserts that language is what contains carrier culture; a person without a language has no identity. Then, he concluded that the globalization of English has contributed greatly to the loss of cultural identity of the second English language learners and they forget their first cultural identity.
The result of the present study is in line with the Alfarhan' study in which MPTs of 14-16-year-old EFL learners were higher than MPTs of 16 to 18; it proves the fact that young EFL learners receive foreign culture easier than the older group. And if the norms and values of the native language neglected, they may experience cultural identity loss.

\section{Conclusion and Implications}

As it was mentioned previously, this study aimed to investigate the Iranian high school EFL learners' multicultural personality traits (MPTs) based on their differences in age. Based on the result, it was concluded that the younger group of learners exhibited more cultural empathy and were more open-minded than the older group, but there was not any significant difference between these two groups in terms of social initiative, emotional stability, and flexibility. Students with high cultural empathy are the best who can understand others culture and benefit from it. Open-mindedness alludes to the nonappearance of unbending biases towards other social bunches, their behaviors, and social propensities and to open state of mind towards those groups. Therefore, the open-minded EFL learners have less difficulty in perceiving different ideas and approaching different cultures. Cultural empathy is depicted as an intrigued in other individuals and an affectability towards others sentiments and beliefs [30]. Moreover, cross-cultural communication between individuals of distinctive social foundations continuously meets challenges in numerous perspectives. The two regions' social traditions, beliefs, and convictions may be totally diverse, and it is these diverse variables that make potential deterrents to cross-cultural 
communication. Mistaken assumptions between them are more likely to lead to genuine cultural conflicts. In arrange to decrease superfluous misfortune, the thought of cultural empathy is imperative [31]. Hence, higher range of cultural empathy is effective for an English language learner to solve problems generated by two totally different cultures.

It is understood that beside other important factors, culturally empathetic and open-mindedness are important factors in learning a foreign language [14]. It can be concluded that young students with high factors of MPTs can be better in learning a foreign language. Moreover, by improving younger students MPTs, especially open-mindedness and cultural empathy, teachers can help them to reach language learning purposes and desired goals. However, teachers should bear in mind the cultural differences and the native language norms to minimize the possibility of cultural loss of EFL learners.

The findings of this study can be considered as helpful guidelines for the teachers, learners, and syllabus designers. Teachers should pay attention to the purpose of their class, the learners' own culture, and the age of their learners, and they should deal with the target culture critically. The finding of this study indicated the necessity for a balanced view of culture, that is, the target culture should not be censored totally, and it should not be taught without critical evaluation. Teachers should be aware that they are not the enforcers of a foreign culture but the promoters of their own culture. Moreover, teachers should be conscious of the fact that some of their learners are worried about cultural invasion as the outcome of teaching the target culture in ELT, and so, the learners should be taught that learning about a culture does not mean abandoning their own culture.

Furthermore, syllabus designers and book writers should be familiar with the learners' needs about culture; therefore, they will design the cultural preparation courses and books with the consideration of these needs. They can design the books with exercises containing more practice of form of the language and mechanics of cultural issues. Syllabus designers, materials developers, and curriculum designers are advised to implement changes in EFL textbooks and course syllabuses to put more emphasis on cultural knowledge towards teaching.

There are some suggestions for researchers who are willing to conduct a research in line with the current study to reach invaluable outcomes. First, this study did not examine the effect of gender. Therefore, future research can consider it as a variable, investigate its effect on the related study, and benefit from it. Second, future investigators can add interview part in spite of distributing questionnaires to students and exploit it in qualitative part of their research.

\section{Data Availability}

The data used to support the findings of this study are available from the corresponding author upon request.

\section{Disclosure}

The authors confirm that the ideas expressed in the submitted article are of their own and not those of any official position of the institution or funder.

\section{Conflicts of Interest}

The authors declare that they have no conflicts of interest.

\section{References}

[1] R. Kirkpatrick, Ed., English Language Education Policy in the Middle East and North Africa, Springer International Publishing, Berlin, Germany, 2017.

[2] J. F. Stein, "The representation of egocentric space in the posterior parietal cortex," Behavioral and Brain Sciences, vol. 15, no. 4, pp. 691-700, 1992.

[3] I. Cakir, "Developing cultural awareness in foreign language teaching," The Journal of Distance Education, vol. 7, no. 3, 2006.

[4] H. D. Brown, Principles of Language Learning and Teaching, Prentice Hall Regents, Hoboken, NJ, USA, 1994.

[5] M. Khatib and H. Samadi Bahrami, "Multicultural personality traits development in an EFL context: the case of Iranian EFL students at BA, MA and Ph. D. Levels," Iranian Journal of Applied Linguistics, vol. 16, no. 2, pp. 53-81, 2013.

[6] G. Li, "Biliteracy and trilingual practices in the home context: case studies of Chinese-Canadian children," Journal of Early Childhood Literacy, vol. 6, no. 3, pp. 355-381, 2006.

[7] C. Kramsch, Context and Culture in Language Teaching, Oxford University Press, Oxford, UK, 1993.

[8] D. Matsumoto and L. Juang, "Culture and psychology," Cengage Learning, 2012.

[9] R. F. Baumeister, C. N. DeWall, N. J. Ciarocco, and J. M. Twenge, "Social exclusion impairs self-regulation," Journal of Personality and Social Psychology, vol. 88, no. 4, pp. 589-604, 2005.

[10] A. W. Schwartz, J. S. Abramson, I. Wojnowich, R. Accordino, E. J. Ronan, and M. R. Rifkin, "Evaluating the impact of the humanities in medical education," Mount Sinai Journal of Medicine: A Journal of Translational and Personalized Medicine, vol. 76, no. 4, pp. 372-380, 2009.

[11] C. T. Kwantes and S. Glazer, Culture, Organizations, and Work: Clarifying Concepts, Springer International Publishing, Berlin, Germany, 2017.

[12] M. Tomasello, The Cultural Origins of Human Cognition, Harvard University Press, Cambridge, MA, USA, 2009.

[13] J. P. Campbell, "Speaker recognition: a tutorial," Proceedings of the IEEE, vol. 85, no. 9, pp. 1437-1462, 1997.

[14] J. A. Fishman, "Reversing language shift," Clevedon: Multilingual Matters, vol. 76, 1991.

[15] C. Baker, Foundations of Bilingual Education and Bilingualism, Multilingual Matters, Bristol, UK, 2011.

[16] I. Alfarhan, "English as a global language and the effects on culture and identity," American Research Journal of English and Literature, vol. 1, pp. 1-6, 2016.

[17] P. J. Corr and G. Matthews, Eds., The Cambridge Handbook of Personality Psychology, Cambridge University Press, Cambridge, UK, 2020.

[18] J. G. Ponterotto, S. O. Utsey, and P. B. Pedersen, "Preventing prejudice: a guide for counselors, educators, and parents," Sage Publications, vol. 2, 2006.

[19] M. Ramirez III, Multicultural Psychotherapy: An Approach to Individual and Cultural Differences, Allyn \& Bacon, Boston, MA, USA, 1999.

[20] K. I. Van Der Zee and J. P. Van Oudenhoven, "The Multicultural Personality Questionnaire: a multidimensional instrument of multicultural effectiveness," European Journal of Personality, vol. 14, no. 4, pp. 291-309, 2000. 
[21] B. D. Ruben, "Assessing communication competency for intercultural adaptation," Group \& Organization Studies, vol. 1, no. 3, pp. 334-354, 1976.

[22] W. Arthur Jr and W. Bennett Jr, "The international assignee: the relative importance of factors perceived to contribute to success," Personnel Psychology, vol. 48, no. 1, pp. 99-114, 1995.

[23] L. Leone, K. I. van der Zee, J. P. van Oudenhoven, M. Perugini, and A. P. Ercolani, "The cross-cultural generalizability and validity of the Multicultural Personality Questionnaire," Personality and Individual Differences, vol. 38, no. 6, pp. 1449-1462, 2005.

[24] J. J. Gumperz, "On teaching language in its sociocultural context," in Social Interaction, Social Context, and LanguagePsychology Press, Hove, UK, 2014.

[25] D. O’Neil, "Language and culture: an introduction to human communication," 2005, http://anthro.palomar.edu/language.

[26] A. Gojkov-Rajić and J. Prtljaga, "foreign language learning as a factor of intercultural tolerance," Procedia-Social and Behavioral Sciences, vol. 93, pp. 809-813, 2013.

[27] L. V. Mikhaleva and J.-C. Régnier, "Parallel study of native and target-language cultures in foreign language teaching," Procedia-Social and Behavioral Sciences, vol. 154, pp. 118-121, 2014.

[28] K. I. Van der Zee and J. P. Van Oudenhoven, "The multicultural personality questionnaire: reliability and validity of self- and other ratings of multicultural effectiveness," Journal of Research in Personality, vol. 35, no. 3, pp. 278-288, 2001.

[29] S. Hayakawa and B. Keysar, "Using a foreign language reduces mental imagery," Cognition, vol. 173, pp. 8-15, 2018.

[30] I. Krasner, "The role of culture in language teaching," Dialog on Language Instruction, vol. 13, no. 1-2, pp. 79-88, 1999.

[31] Y. Jiang and J. Wang, "A study of cultural empathy in foreign language teaching from the perspective of cross-cultural communication," Theory and Practice in Language Studies, vol. 8, no. 12, p. 1664, 2018. 